\title{
"Rare Ovarian Tumours: Epidemiology, Treatment Challenges in and outside a Network Setting."
}

I Ray-Coquard, AnnaLisa Trama, MJ Seckl, C Fotopoulou, P Pautier, S Pignata, G Kristensen, G Mangili, H. Falconer, L. Massuger, J Sehouli,E Pujade-Lauraine, D Lorusso, F Amant, E Rokkones, I Vergote, JA Ledermann.

1. Dpt of Medical oncology Centre Leon Berard, University Claude Bernard Lyonl, Lyon France

2. AnnaLisa Trama, Fondazione IRCCS istituto nazionale dei tumori Milan

3. Charing Cross Hospital Campus of Imperial College London Fulham Palace Rd London W68RF UK

4. Dept of Surgery and Cancer, Imperial College London, UK

5. Medical oncology Dpt Gustave Roussy institution, Villejuif France

6. Medical Oncology, Department of Urology and Gynecology, Istituto Nazionale Tumori - IRCSS Fondazione G. Pascale Naples Italy

7. Dept of Gynecologic Oncology and Institute for Cancer Genetics and Informatics, Oslo University Hospital, Oslo, Norway

8. Department of Obstetrics and Gynecology, San Raffaele Scientific Institute, Milan, Italy

9. Department of Women's and Children's Health Division of Obstetrics and Gynecology Karolinska Institutet/University Hospital 17176 Stockholm, Sweden

10. Department of Obstetrics and gynaecology Radboudumc PO Box 9101, 6500 HB Nijmegen, The Netherlands

11. Department of Gynecology with Center for Oncological Surgery, European Competence Center for Ovarian Cancer Campus Virchow Klinikum, Medical University of Berlin

12. AP-HP, Université Paris Descartes

13. Gynecologic oncology unit, Fondazione IRCCS istituto nazionale dei tumori Milan

14. Center Gynaecologic Oncology Amsterdam (CGOA), Netherlands Cancer Institute and University of Amsterdam \& Gynaecologic Oncology KU Leuven

15. Dept. of Gynaecological Oncology, The Norwegian Radium Hospital, Divison of Cancer Medicine

16. Oslo University Hospital, POBox 4950 Nydalen, 0424 Oslo, NORWAY

17. Gynaecological Oncologist, University Hospital Leuven, Herestraat 49, B-3000 Leuven, Belgium, European Union

18. UCL Cancer Institute, University College London, UK 


\section{Abstract}

Purpose of the review: More than $50 \%$ of all gynaecological cancers can be classified as rare tumours (defined as an annual incidence of $<6$ per 100,000) and such tumours represent an important challenge for clinicians.

Recent findings: Rare cancers account for more than one fifth of all new cancer diagnoses, more than any of the single common cancers alone. Reviewing the RARECAREnet database, some of the tumours occur infrequently, whilst others because of their natural history have a high prevalence, and therefore appear to be more common, although their incidence is also rare. Harmonization of medical practice, guidelines and novel trials are needed to identify rare tumours and facilitate the development of new treatments. Ovarian tumours are the focus of this review, but we comment on other rare gynaecological tumours, as the diagnosis and treatment challenges faced are similar.

Future: This requires European collaboration, international partnerships, harmonization of treatment and collaboration to overcome the regulatory barriers to conduct international trials. Whilst randomized trials can be done in many tumour types, there are some for which conducting even single arm studies may be challenging. For these tumours alternative study designs, robust collection of data through national registries and audits could lead to improvements in the treatment of rare tumours. In addition, concentring the care of patients with rare tumours into a limited number of centres will help to build expertise, facilitate trials and improve outcomes.

\section{Introduction}

Until recently the three most common types of gynaecological cancer (epithelial ovarian, cervical and uterine tumours) have been managed as individual entities and few adjustments have been made for histological subtype(1). The term 'rare tumour' referred mostly to non-epithelial subtypes. However, it is now clear that different histologic epithelial subtypes of ovarian, endometrial and cervical cancers, have distinct pathological behaviour patterns that place many more of these tumours into a 'rare' category, defined as an annual incidence of $\leq 6$ per 100,000 (www. Rarecare.net.eu). Within these subtypes, it is often difficult to define clearly the natural history, prognostic factors as well as a definitive histological diagnosis in some of these tumours because they are so rare $(2 ; 3)$.

Defining a clear treatment strategy is often difficult as there is often considerable variability in age, histology, pattern of distribution and stage(4). As it has not been feasible to conduct large-scale randomized trials in these rare gynaecologic cancers, treatments have generally been developed based on expert opinion or by drawing on experience from either more common types of gynaecological cancers, or from other tumours with some pathologic similarities. This weak knowledge-based approach means that it is difficult to evaluate new cancer therapies in these rare tumours or apply the therapeutic advances made in treating other tumours. As a consequence, clinical or biological research and management with surgery, radiotherapy and 
systemic treatment is frequently not optimal $(5 ; 6)$. In this review we focus on rare ovarian tumours, but the challenges we face with these tumours are common to other gynaeological tumours, and we include these in the discussion of opportunities to overcome current barriers to improving diagnosis, treatment and research.

\section{Challenges}

\section{Epidemiology (table 1)}

RARECAREnet is a 3-year project co-funded by the European Commission (EC), which started in 2012 and contributed among other projects to the creation of networks of action for rare diseases. The Fondazione IRCCS Istituto Nazionale dei Tumori (Milan, Italy) was the leading organization and more than 20 European Institutions and Organizations participate in the project as associated or collaborating partners. The RARECAREnet database was drawn from the dataset of EUROCARE-5, the wider collaborative study on cancer patients' survival in Europe (www.eurocare.it). Overall 94 European population-based cancer registries (CRs) participating in EUROCARE-5 adhered also to the RARECAREnet project. They provided information on cancer patients diagnosed up to 2007 and followed-up for outcomes to the end of 2008 or later. Overall, 27 countries were represented in the project, and among them:

- 19 countries were covered by national CRs (Austria, Bulgaria, Czech Republic, Croatia, Estonia, England, Finland, Iceland, Northern Ireland, Latvia, Lithuania, Malta, Norway, Republic of Ireland, Slovakia, Slovenia, Scotland, The Netherlands, Wales);

- 8 countries were covered by regional CRs partially representing the population of their country (Belgium, France, Germany, Switzerland, Italy, Portugal, Poland, and Spain).

The mean European population covered, over the period 2000-2007, was about 207,942,000, corresponding to $48 \%$ of the population of countries participating in RARECAREnet and $46 \%$ of the European Union population (excluding Norway, Switzerland, and Iceland, which are not EU members) (7). The list (http://www.rarecarenet.eu/rarecarenet/index.php/cancerlist) is derived from the data of population-based cancer registries from 27 European countries adhering to the RARECAREnet project (8-10).

\section{Incidence}

With an incidence rate of $16 / 100,000$ corresponding to about 87,000 new EU annual cases, the sum of all rare gynaecological tumours (RGT), including ovarian, fallopian tube, uterine, cervical, vaginal, and vulvar cancers, represent more than $50 \%$ of all gynaecologic malignancies, are an important challenge for clinicians (11).

Out of the overall RGT diagnosed between $2000-2007$, 48\% were rare ovarian tumours. Rare eepithelial ovarian cancers were the most common entity, with a crude incidence rate of 7.3 per 100,000 going down to $1.2 / 100,000$ considering the very rare epithelial tumours and excluding the adenocarcinoma of ovary; non epithelial ovarian cancers are all rare with an incidence rate of 0.25 per 100,000 (table 1).

Among rare epithelial tumours of the ovary, $63 \%$ were mucinous adenocarcinomas, $25 \%$ were clear cell adenocarcinomas and 12\% MMMT (Mixed mesodermal malignant tumours [now classified as Carcinosarcoma]). The incidence increased moderately with age for these cancers, contrary to other frequent epithelial ovarian cancers.

Among sex cord tumours, granulosa cell tumours were the most common histotypes ( $90 \%$ of cases) while Sertoli-Leydig cell tumours accounted for $4 \%$ of cases; the remaining were few cases of several histotypes (thecoma malignant, Sertoli cell or Leydig pure cell tumours NOS, malignant steroid cell tumours). Among germ cell tumours, the most common histologies were immature teratomas (42\%), followed by 
dysgerminomas (33\%), Yolk sac tumours (15\%) and mixed germ cell tumours (4\%); the remaining were few cases of different histotypes (embryonal carcinoma, polyembryoma, choriocarcinoma combined with other germ cell elements, choriocarcinoma, NOS). Germ cell tumours were mostly diagnosed among children and young adults, with median age at 27 years (range 1-81) and 36 years (range 2-98) respectively. Sex cord tumours occurred mainly in adulthood (median age was 56 years, range 6-93).

\section{Survival}

Five-year relative survival (RS) was $54 \%$ (95\% Cl 53.6-55.3) for very rare epithelial tumours of ovary and $82 \%$ (95\% $\mathrm{Cl} 81-84)$ for non-epithelial ovarian cancers. Among the rare epithelial tumours the carcinosarcomas were those with the worse prognosis. A fairly good prognosis was observed for all the histotypes of nonepithelial tumours of ovary, with germ cell tumours having slightly better prognosis ( 5 -year $\mathrm{RS} 85 \%$; $95 \% \mathrm{Cl}$ 83-87) than sex cord tumours (5-year RS 79\%; 95\% Cl 77-81) (Table 3). Survival differences by age and histotype were marked in some cases with older patients ( $<65$ years) having always the worse prognosis (Table 4). Interestingly, survival data within the European Union varied slightly by region with Eastern Europe having generally lower survival than the other areas (Figure 1). Geographic variation in survival for these cancers might reflect differences in the use of effective treatment protocols and health care organisation for these rare cancers.

\section{Complete Prevalence}

In the EU in 2008 about 119,000 women were expected to be alive with a past diagnosis of a rare ovarian cancer (excluding adenocarcinoma of ovary): 86,000 had a diagnosis of rare epithelial ovarian cancers (mucinous adenocarcinoma, clear cell adenocarcinoma, and carcinosarcoma; 31,369 had a diagnosis of nonepithelial ovarian cancers.

These data derived from the largest available database on rare cancers obtained from European CRs. For rare cancers, the most likely quality problem is lack of specificity of morphology codes making it impossible to assign such cases to a specific histology. Unspecified morphology can be due to genuine difficulty in assigning a specific morphological category or because inadequate documentation was supplied to the CR when the case was registered. The latter is registration bias and results in incidence and prevalence underestimation. To assess the extent of registration bias, RARECARE reviewed the original data (mainly pathologic reports) of a selected sample (about 18,000 cases) of eight rare cancers (Trama A, Tumori Journal). Briefly, the great majority of NOS morphology cases were confirmed as NOS. The few NOS cases that changed to a more specific diagnosis generally increased the incidence of the more common cancer forms. This finding suggests that the problem with poorly specified morphology cases is mainly one of difficulty in reaching a precise diagnosis, not registration bias.

Reaching a correct pathological diagnosis in rare tumours can be challenging, not only because of the rarity of a condition, but also because these tumours may have an unusually complex histotypic appearance. For these reasons, the correct diagnosis may be more easily obtained by expert and centralized pathological review. A recently published work on central review of rare ovarian tumours reported a modification of the diagnosis between 9 to $37 \%$ of cases $(12 ; 13)$. Thus, recording data in a rare tumour database alone is not sufficient for collecting information on rare tumours. Consideration is needed to ensure accurate recording of histopathological data within an expert pathology setting and central pathology review when required. A further limitation of the data reported by European registries is that coverage of European areas is not homogeneous; more than $50 \%$ of the recorded cases were diagnosed in the UK and Nordic countries. One of the key reasons is that national registries are concentrated in these areas, while in Central and Southern 
Europe registries are mostly locally organized. Furthermore, Eastern Europe is represented by only two registries.

\section{Quality management for rare gynaecologic cancers.}

Whilst guidelines are helpful in providing a degree of harmonization of treatment, it is clear that the management of rare gynaecological tumours is particularly complex and requires a multi-disciplinary approach. Pathologists, radiologists, surgeons, radiation therapists, medical oncologists and paediatric oncologists, play a key role in most cases. In some situations an even broader range of support from clinicians from other disciplines is needed. Adequate knowledge of these neoplasms is essential for an accurate diagnosis, the choice of surgical treatment, adjuvant therapy and effective medical treatment at relapse. This can be provided by involving reference centres for gynaecological cancers to centralise diagnosis and care, or by the establishment of reference networks that share their multidisciplinary expertise creating an environment in which a high volume of patients are treated each year. Such centres are also involved in clinical trials, which include a high proportion of patients with gynaecological cancers (14). In France, a dedicated rare gynaecologic cancer network has been created to diagnose and manage rare tumours. This allows French physicians to seek advice on the diagnosis and surgical and medical management of the patients through a dedicated regional or national expert panel of multidisciplinary staff (15). Patients are registered through a website that also provides national guidelines, an updated bibliography and information for patients and families. Given the rapid success of this experience with patients and physicians, the scientific board decided in 2008, with a substantial financial support from the French Cancer Institute (INCa), to broaden the scope of the website and offer clinical information and collect biological samples (16).

However, in the past 5 years there has been an explosion in our understanding of the heterogeneity of gynaecological cancers, so a global approach is needed to share information and collect complex biological and clinical data for research into the treatment of these rare tumours. Although the management of RGTs by oncologists and gynaecologists is now much better organized at a national level, no specific structured collaborations exist internationally. Consequently, in 2012 the GCIG (Gynaecologic Cancer Intergroup) an organization of national gynaecological cancer trials groups decided to develop a collaborative research initiative and clinical trials in 'moderately rare' and 'very rare' gynaecological cancers (17). The main objectives were: 1 ) to define current recommendations for the management of rare gynaecologic tumours; 2) to define control arms for present and future clinical trials involving these cancers and to prioritize and design international initiatives in rare gynaecologic cancers. The first step for the GCIG was to develop clinical management guidelines for the major histological subtypes of rare tumours. To achieve this the major national groups formulated a series of documents to harmonize the management of first line and relapsed treatment of twenty specific rare gynaecological cancers. (These were published in 2014 in the International Journal Gynaecologic Cancer). The next step will be to use these documents to design and develop clinical trials in these tumours to improve the outcome of treatment (18).

\section{Dedicated studies design for rare gynaecologic cancers}

Establishing surgical trials requires a concentration of committed surgeons and enrolment of a sufficiently large group of patients. For novel systemic therapy trials in rare tumours there may not be a clear 'lead' compound, as these are frequently being sought in more common tumours. However, as our understanding of the molecular nature of rare gynaecological cancers grows, and the number of new compounds emerging 
increase it is important to review which of these agents might also be considered appropriate for trials in rare gynaecological tumours.

\section{Uncommon variants of gynaecologic cancers}

It is clear that with a restriction in the number of patients available for trials novel designs are needed to explore the activity of a number of potential compounds. Furthermore, access to these novel drugs can be difficult; most are developed through the pharmaceutical industry and it can be difficult to persuade industry to invest resources to the study of rare tumours. Here, academic leadership is key; firstly for leverage of academic funding and secondly to engage with industry. It also requires a commitment from the clinical community and local institutions; setting up trials for only a few patients is costly, and enthusiasm to recruit only a few patients per year is challenging. This can be helped by establishing referral networks to centralise care within clinical trials for these few patients. However, even with the best intentions running randomised trials can be problematic. An international trial in mucinous ovarian cancer (mEOC/GOG241), opened in multiple sites closed early due to poor recruitment. The reasons ranged from the rarity of the disease(less common than predicted with only $47 \%$ confirmed on pathological review to have the disease) to difficulties in funding chemotherapy drugs that were given out of licence (Gore et al ASCO 2015). Methods advocated for clinical trials in rare diseases are not necessarily applicable in rare cancers, and the choice of method used is related to where the cancer lies on a sliding scale of rarity. The approaches that we discussed will enable evidence-based clinical practice for rare cancers in the future, particularly in the rapidly developing era of molecularly defined cancers. Methods outside the conventional approach might not be ideal, but pragmatic solutions have to be sought to enable some level of evidence-based health care in this setting (19). Bayesian or adaptive designs or MAMS (multi-arm multistage) trials are options to consider when evaluating multiple new agents in a randomized setting (20). New agents can be introduced without stopping and re-starting protocols by using a single protocol with subsequent substantial amendments as new drugs are introduced (21). Exploration of methods for the design and analysis of clinical studies of rare diseases continues to be a research priority, as evidenced by three projects funded by the European Union within the 7th Framework Programme (ASTERIX: FP7 HEALTH 2013-603160; IDEAL: FP7 HEALTH 2013-602552; INSPIRE: FP7 HEALTH 2013-602144). Such methodological developments could further improve assessments of new treatments in rare cancers, reduce the administrative costs of a trial and increase efficiency by avoiding some of the regulatory barriers and ultimately improve patient care.

\section{Very rare tumours}

Single arm phase II trials are usually criticized as results may be confounded by selection bias. They continue to be performed but interpretation of results can be difficult (22). To avoid such bias, alternative statistical methods such as a randomized Bayesian design (23) can be used. For example, for sex-cord stromal tumours, a GCIG randomized trial (Alienor trial) exploring bevacizumab in combination with weekly paclitaxel or chemotherapy alone, led by the French Group (GINECO) (NCT01770301) has been launched. By using a Bayesian statistical plan, only 60 patients are needed to compare two treatment groups of women with this rare tumour. Alternative strategies to a randomized trial include using a historical control group a randomized discontinuation design, or using the patient as their own control to compare PFS results with a previous line of therapy (24) have all been considered as a means of overcoming the challenge of recruiting an adequate number of patients to trials in rare tumours

However, for very rare tumours it is very unlikely that progress will be made through even single arm phase II trials. Prospective collection of data through national or still better international tumour registries may be 
the simplest and most cost-effective way forward to learn about rare tumours, harmonize treatments and improve outcome through repeated audit of data. Established database repositories can be adapted (e.g. http://project-redcap.org), or a customized approach can be developed. The experience of the French GINECO group, supported by the National Cancer Institute (INCa) on a national network (http://www.ovairerare.org), including collection of more than 8000 patients provides important data to improve clinical management and research at the national level (25). It is particularly important that in addition to collecting clinical data registries also gain access to tumour and blood samples for molecular analysis.

Clinical databases collecting information on biological characteristics of rare cancers and on their patterns of care should also highly contribute to increase the knowledge of these tumours and improve their clinical management.

\section{Need for international collaborations}

Notwithstanding the difficulties of conducting trials in rare tumours the randomized trial provides the highest level of evidence to support a new treatment for gynaecological cancers, and it has been the key approach used by regulatory authorities to approve new drugs. Multi-centre national clinical trials, often with international collaboration are needed to improve the treatment of even relatively common gynaecological cancers. The GCIG, established in 1997 now has a network of 28 national gynaecological cancer trials groups that are committed to developing better treatments through international collaboration (26). The value of such collaboration is even greater when researching rare tumours.

An International Rare Cancer Initiative (IRCI) has been established specifically to deal with some of these challenges. A consortium established by Cancer Research UK (CRUK), the National Institute of Health Research Clinical Research Network: Cancer (NIHR CRN:Cancer), the National Cancer Institute (NCI), the European Organisation for Research and Treatment of Cancer (EORTC), the Institute National Du Cancer (INCa) and the National Cancer Institute of Canada Clinical Trials Group (NCIC CTG)(27;28). IRCI has now approved a randomized trial in advanced high grade undifferentiated uterine sarcoma that will compare maintenance carbozantinib with placebo after response to chemotherapy (NCT01979393).

Clinical databases collecting information on biological characteristics of rare cancers and on their patterns of care should also highly contribute to increase the knowledge of these tumours and improve their clinical management. Genomic dataset of these patients and collaboration with experienced genomic cores will be fundamental, even rare cancers may have a different genomic pattern and deserve a different approach. Also, the interpretation of clinical studies may benefit from linking response to genomic characteristics. An example of this type of databases is the French website (www.ovaire-rare.org) developed to collect clinical cases and tumour samples of rare ovarian cancers to define better prognostic factors and to develop specific trials.

One way to overcome these challenges, would be to establish centres of expertise for these rare cancers. An example of what can be achieved through centralized care of a rare gynaecological malignancy is provided by the UK system for managing gestational trophoblastic disease (29). This has played a central role in developing new internationally adopted management strategies that have transformed survival rates from what used to be a universally lethal outcome to one where nearly all women are cured (30). As a consequence of this, other groups across the world are establishing their own centres including Europe, where a network (EOTTD.org) has been established. It is now necessary for us to envisage networks of such centres for other 
rare gynaecological cancers across the EU to thereby achieve the necessary organizational structure and critical mass to carry out clinical trials, optimise patient care and improve the biological knowledge of these diseases. The European Commission is implementing the Directive 2011/24/EU of the European Parliament and the Council of 9 March 2011 on the application of patients' rights in cross-border healthcare. In principle, this Directive is meant to grant EU patients the right to access safe and good-quality treatment across EU borders. A "by-product" of all this is the creation of the European Reference Networks (ERNs), as a means to provide "highly specialised healthcare for rare or low-prevalence complex diseases" (31).The formal activation of ERNs in 2017 will be a cornerstone in the EU cooperation on rare cancers. Thus, it was decided that the Joint Action on Rare Cancers (JARC) of the European Public Health Programme should be instrumental to this (32). In fact, JARC aims to optimise the creation process of the ERNs, by providing them with operational solutions and professional guidance in the areas of quality of care, epidemiology, research and innovation, education and state of the art definition on prevention, diagnosis and treatment of rare cancers. JARC was launched in October 2016 to support cooperation between the Commission and the Member States. Coordinated by the Instituto Nazionale dei Tumori of Milan (Italy) JARC takes advantage of a strong partnership of 34 partners and 18 European Member States. This is viewed as a great opportunity to improve patient care and research in rare cancers within Europe.

In the course of their work on European Centres of Reference (ECR), a Working Group of medical care and health services (comprised of representatives from member states) has decided to seek advice from an expert group on Centres of Reference on several specific issues. European Reference Networks (ERNs) for rare diseases should serve as research and knowledge centres, updating and contributing to the latest scientific findings, treating patients from other Member States and ensuring the availability of subsequent treatment facilities where necessary. In 2016, an EU call for rare cancer was set up and several countries applied to become an EU network dedicated to rare adult cancers. EURACAN (RAre Adult CANcer) aims to establish a world-leading, patient-centric and sustainable network of multidisciplinary research-intensive clinical centre focused on rare adult cancers (RAC) with the underlying vision to i) standardize and improve the quality of care of all RAC in European adult patients and ii) ensure an optimised access to clinical innovation in the field of RAC and across all Member States (MS) (figure 2). With associate partners, in particular patients advocacy groups, preparation and dissemination of multilanguage information documents on the nature of the disease, treatments, management, reference centers for treatment and appropriate contacts within patients advocacy groups as well as patient education and empowerment will be developed.

\section{Conclusions}

National experiences from reference networks have shown that providing information to the primary care physicians, and a national coordination of diagnostic procedures facilitates adherence to clinical practice guidelines (6). All these experiences are clearly favourable to the management of rare cancers, and result in less delay in treatment that is frequently seen when diagnosis and treatment decisions are made without specialised input (6). High quality management of rare gynaecologic cancers needs to be based on scientific evidence that should include, international consensus guidelines, multidisciplinary managed care, and high quality clinical trials. The organisation should take account of national and local structures and can be facilitated by having reference centres for gynaecological cancers and/or reference networks sharing multidisciplinary expertise and access to clinical trials, so that information gathering and sharing of results is a coordinated approach to the treatment of a large number of patients each year (33). Patients and patient advocacy groups should take part in the development of these European networks! Conducting trials in a small number of patients presents its own challenges; novel trial design, overcoming regulatory barriers for 
international collaboration and funding of studies in rare tumours by academic bodies with little or no pharmaceutical support. The survival differences (RERACARE project (34)) by histotype, confirmed that the considered rare gynecological cancers, as many other infrequent cancers, present several challenges due to their rarity. Their diagnosis requires expertise and centralized review. Their natural history is poorly understood and prognostic factors have to be clarified. Many of these difficulties can be overcome through the establishment of robust international collaborations that harmonize the approach to clinical trials. However, there remain diseases for which clinical trials are virtually impossible to perform. For these we need reliable data collection by national registries that can be merged to form international data sets.

Table 1. Crude and age adjusted incidence rate (IR per 100,000) of rare ovarian cancers by histology with $95 \%$ Confidence Intervals $(95 \% \mathrm{Cl})$ in the RARECAREnet database

\begin{tabular}{|l|l|l|l|l|l|l|}
\hline & Crude IR & \multicolumn{2}{l|}{$95 \% \mathrm{Cl}$} & \multicolumn{2}{l|}{ Age adj IR } & \multicolumn{2}{l|}{$95 \% \mathrm{Cl}$} \\
\hline Rare epithelial tumours of ovary & $\mathbf{1 . 2 2}$ & $\mathbf{1 . 2 0}$ & $\mathbf{1 . 2 3}$ & $\mathbf{1 . 0 5}$ & $\mathbf{1 . 0 4}$ & $\mathbf{1 . 0 7}$ \\
\hline Mucinous adenocarcinoma of ovary & 0.77 & 0.76 & 0.78 & 0.67 & 0.66 & 0.68 \\
\hline Clear cell adenocarcinoma of ovary & 0.30 & 0.29 & 0.31 & 0.27 & 0.26 & 0.28 \\
\hline Carcinosarcoma of ovary & 0.14 & 0.14 & 0.15 & 0.12 & 0.11 & 0.12 \\
\hline Non epithelial tumours of ovary & $\mathbf{0 . 2 5}$ & $\mathbf{0 . 2 4}$ & $\mathbf{0 . 2 6}$ & $\mathbf{0 . 2 4}$ & $\mathbf{0 . 2 3}$ & $\mathbf{0 . 2 5}$ \\
\hline Sex cord tumours of ovary & $\underline{\mathbf{0 . 1 2}}$ & $\underline{\mathbf{0 . 1 2}}$ & $\underline{\mathbf{0 . 1 3}}$ & $\underline{\mathbf{0 . 1 1}}$ & $\underline{\mathbf{0 . 1 1}}$ & $\underline{\mathbf{0 . 1 2}}$ \\
\hline Granulosa cell tumours malignant & 0.11 & 0.11 & 0.12 & 0.10 & 0.10 & 0.10 \\
\hline Sertoli Leidig cell tumours & 0.00 & 0.00 & 0.01 & 0.00 & 0.00 & 0.01 \\
\hline Other sex cord tumours of ovary & 0.01 & 0.01 & 0.01 & 0.01 & 0.01 & 0.01 \\
\hline Germ cell tumour of ovary & $\underline{\mathbf{0 . 1 3}}$ & $\underline{\mathbf{0 . 1 2}}$ & $\underline{\mathbf{0 . 1 3}}$ & $\underline{\mathbf{0 . 1 3}}$ & $\underline{\mathbf{0 . 1 2}}$ & $\underline{\mathbf{0 . 1 3}}$ \\
\hline Yolk sac tumors & 0.02 & 0.02 & 0.02 & 0.02 & 0.02 & 0.02 \\
\hline Dysgerminoma & 0.04 & 0.04 & 0.05 & 0.04 & 0.04 & 0.05 \\
\hline Mixed germ cell tumors & 0.01 & 0.00 & 0.01 & 0.01 & 0.00 & 0.01 \\
\hline Malignant/Immature teratomas of ovary & 0.05 & 0.05 & 0.06 & 0.05 & 0.05 & 0.06 \\
\hline Other germ cell tumours of ovary & 0.01 & 0.00 & 0.01 & 0.01 & 0.00 & 0.01 \\
\hline
\end{tabular}


Table 2. Age specific incidence rate (IR per 100,000) of rare ovarian cancers by histology with 95\% Confidence Intervals (95\%Cl) in the RARECAREnet database

\begin{tabular}{|c|c|c|c|c|c|c|c|c|c|c|c|c|}
\hline \multirow[b]{3}{*}{ Rare epithelial tumours of ovary } & \multicolumn{3}{|c|}{$00-14$ years } & \multicolumn{3}{|c|}{$15-24$ years } & \multicolumn{3}{|c|}{$25-64$ years } & \multicolumn{3}{|c|}{$65+$ years } \\
\hline & \multirow{2}{*}{$\begin{array}{r}\text { IR } \\
0.001\end{array}$} & \multicolumn{2}{|c|}{$95 \% \mathrm{Cl}$} & \multirow{2}{*}{\begin{tabular}{|l|} 
IR \\
0.118 \\
\end{tabular}} & \multicolumn{2}{|c|}{$95 \% \mathrm{Cl}$} & \multirow{2}{*}{$\begin{array}{l}\frac{I R}{1.312} \\
\end{array}$} & \multicolumn{2}{|c|}{$95 \% \mathrm{Cl}$} & \multirow{2}{*}{\begin{tabular}{|l|} 
IR \\
3.055
\end{tabular}} & \multicolumn{2}{|c|}{$95 \% \mathrm{Cl}$} \\
\hline & & 0.000 & 0.003 & & 0.104 & 0.134 & & 1.288 & 1.337 & & 2.986 & 3.124 \\
\hline Mucinous adenocarcinoma of ovary & 0.001 & 0.000 & 0.003 & 0.113 & 0.099 & 0.129 & 0.837 & 0.818 & 0.857 & 1.879 & 1.825 & 1.933 \\
\hline Clear cell adenocarcinoma of ovary & NA & $\mathrm{NA}$ & NA & 0.004 & 0.002 & 0.008 & 0.369 & 0.356 & 0.382 & 0.640 & 0.609 & 0.672 \\
\hline Mullerian mixed tumour of ovary & NA & $\mathrm{NA}$ & NA & 0.001 & 0.000 & 0.004 & 0.107 & 0.100 & 0.114 & 0.536 & 0.508 & 0.565 \\
\hline Non epithelial tumours of ovary & 0.114 & 0.101 & 0.128 & 0.331 & 0.306 & 0.357 & 0.257 & 0.246 & 0.268 & 0.302 & 0.281 & 0.324 \\
\hline Sex cord tumours of ovary & 0.004 & 0.002 & 0.008 & $\underline{0.026}$ & $\underline{0.019}$ & 0.034 & 0.150 & 0.142 & $\underline{0.159}$ & 0.240 & 0.221 & 0.260 \\
\hline Granulosa cell tumours malignant & 0.003 & 0.001 & 0.006 & 0.017 & 0.012 & 0.024 & 0.137 & 0.129 & 0.145 & 0.214 & 0.197 & 0.233 \\
\hline Sertoli Leidig cell tumours & 0.001 & 0.000 & 0.003 & 0.005 & 0.003 & 0.010 & 0.005 & 0.004 & 0.007 & 0.006 & 0.004 & 0.010 \\
\hline Other sex cord tumours of ovary & 0.000 & 0.000 & 0.001 & 0.003 & 0.001 & 0.006 & 0.008 & 0.007 & 0.011 & 0.019 & 0.014 & 0.025 \\
\hline Germ cell tumour of ovary & 0.110 & $\underline{0.097}$ & $\underline{0.123}$ & $\underline{0.305}$ & $\underline{0.281}$ & $\underline{0.330}$ & $\underline{0.107}$ & $\underline{0.100}$ & $\underline{0.114}$ & $\underline{0.062}$ & $\underline{0.053}$ & $\underline{0.073}$ \\
\hline Yolk sac tumors & 0.019 & 0.014 & 0.026 & 0.050 & 0.041 & 0.061 & 0.017 & 0.014 & 0.020 & 0.004 & 0.002 & 0.007 \\
\hline Dysgerminoma & 0.039 & 0.032 & 0.047 & 0.144 & 0.128 & 0.161 & 0.028 & 0.025 & 0.032 & 0.009 & 0.006 & 0.013 \\
\hline Mixed germ cell tumors & 0.008 & 0.005 & 0.012 & 0.016 & 0.011 & 0.022 & 0.003 & 0.002 & 0.005 & 0.001 & 0.000 & 0.003 \\
\hline Malignant/Immature teratomas of ovary & 0.039 & 0.032 & 0.047 & 0.087 & 0.074 & 0.101 & 0.051 & 0.047 & 0.056 & 0.047 & 0.039 & 0.056 \\
\hline Other germ cell tumours of ovary & 0.005 & 0.002 & 0.008 & 0.008 & 0.005 & 0.013 & 0.007 & 0.005 & 0.009 & 0.002 & 0.001 & 0.005 \\
\hline
\end{tabular}

NE: not estimable because no cases were observed in the period (2000-2007) 
Table 3. Number of cases on which the analyses are based, 5-year relative survival (RS\%) of rare ovarian cancers by histology with $95 \%$ Confidence Intervals $(95 \% \mathrm{Cl})$ in the RARECAREnet database

\begin{tabular}{|l|r|c|c|c|}
\hline & $\mathbf{N}$ & $\mathbf{5}$-year RS (\%) & \multicolumn{2}{|c|}{$\mathbf{9 5 \%} \mathbf{C l}$} \\
\hline Rare epithelial tumours of ovary & $\mathbf{1 9 , 0 0 9}$ & $\mathbf{5 4}$ & $\mathbf{5 3 . 5 9}$ & $\mathbf{5 5 . 2 5}$ \\
\hline Mucinous adenocarcinoma of ovary & 12,010 & 60 & 58.84 & 60.88 \\
\hline Clear cell adenocarcinoma of ovary & 4,761 & 55 & 53.78 & 57.17 \\
\hline Mullerian mixed tumour of ovary & 2,242 & 21 & 19.41 & 23.49 \\
\hline Non epithelial tumours of ovary & $\mathbf{3 , 9 0 6}$ & $\mathbf{8 2}$ & $\mathbf{8 0 . 8 2}$ & $\mathbf{8 3 . 7 1}$ \\
\hline Sex cord tumours of ovary & $\underline{\mathbf{1 , 9 3 7}}$ & $\underline{\mathbf{7 9}}$ & $\underline{\mathbf{7 6 . 8 6}}$ & $\underline{\mathbf{8 1 . 4 9}}$ \\
\hline Granulosa cell tumours malignant & 1,741 & 80 & $\mathbf{7 7 . 7 3}$ & 82.57 \\
\hline Sertoli Leidig cell tumours & $\mathbf{7 4}$ & 68 & 54.55 & 78.96 \\
\hline Other sex cord tumours of ovary & 122 & 72 & 60.12 & 80.38 \\
\hline Germ cell tumour of ovary & $\underline{\mathbf{1 , 9 6 9}}$ & $\mathbf{8 5}$ & $\mathbf{8 3 . 3 8}$ & $\mathbf{8 6 . 8 5}$ \\
\hline Yolk sac tumors & 302 & 86 & 81.30 & 89.78 \\
\hline Dysgerminoma & 659 & 90 & 87.64 & 92.62 \\
\hline Mixed germ cell tumors & 85 & 85 & 74.03 & 91.31 \\
\hline Malignant/Immature teratomas of ovary & $\mathbf{8 2 9}$ & 83 & 80.35 & 86.02 \\
\hline Other germ cell tumours of ovary & 94 & 63 & 50.77 & 72.53 \\
\hline
\end{tabular}


Table 4. Number of cases on which the analyses are based, 5 -year relative survival (RS\%) of rare ovarian cancers by histology with $95 \%$ Confidence Intervals (95\%(C)) in the RARECAREnet database

\begin{tabular}{|c|c|c|c|c|c|c|c|c|c|c|c|c|c|c|c|c|}
\hline \multirow{3}{*}{\begin{tabular}{|l} 
Rare epithelial tumours of ovary \\
\end{tabular}} & \multicolumn{4}{|c|}{$00-14$ years } & \multicolumn{4}{|c|}{$15-24$ years } & \multicolumn{4}{|c|}{$25-64$ years } & \multicolumn{4}{|c|}{$65+$ years } \\
\hline & \multirow{2}{*}{$\begin{array}{l}\mathrm{N} \\
2 \\
\end{array}$} & \multirow{2}{*}{\begin{tabular}{r|} 
RS \\
$50.04 \%$ \\
\end{tabular}} & \multicolumn{2}{|c|}{$95 \% \mathrm{Cl}$} & \multirow{2}{*}{$\begin{array}{r}\mathrm{N} \\
238 \\
\end{array}$} & \multirow{2}{*}{\begin{tabular}{r|} 
RS \\
$87.31 \%$ \\
\end{tabular}} & \multicolumn{2}{|c|}{$95 \% \mathrm{Cl}$} & \multirow{2}{*}{\begin{tabular}{r|r}
$N$ \\
11,166 \\
\end{tabular}} & \multirow{2}{*}{\begin{tabular}{|r|} 
RS \\
$61.75 \%$ \\
\end{tabular}} & \multicolumn{2}{|c|}{$95 \% \mathrm{Cl}$} & \multirow{2}{*}{\begin{tabular}{r|}
$N$ \\
7,603 \\
\end{tabular}} & \multirow{2}{*}{\begin{tabular}{r|} 
RS \\
$41.98 \%$ \\
\end{tabular}} & \multicolumn{2}{|c|}{$95 \% \mathrm{Cl}$} \\
\hline & & & $0.59 \%$ & $91.07 \%$ & & & $82.15 \%$ & $91.06 \%$ & & & $60.74 \%$ & $62.74 \%$ & & & $40.57 \%$ & $43.39 \%$ \\
\hline Mucinous adenocarcinoma of ovary & 2 & $50.04 \%$ & $0.59 \%$ & $91.07 \%$ & 227 & $88.05 \%$ & $82.83 \%$ & $91.76 \%$ & 7,114 & $67.74 \%$ & $66.53 \%$ & $68.91 \%$ & 4,667 & $45.73 \%$ & $43.89 \%$ & $47.55 \%$ \\
\hline Clear cell adenocarcinoma of ovary & 0 & $\mathrm{NE}$ & $\mathrm{NE}$ & $\mathrm{NE}$ & 8 & $74.19 \%$ & $29.61 \%$ & $92.94 \%$ & 3,150 & $57.63 \%$ & $55.62 \%$ & $59.59 \%$ & 1,603 & $51.05 \%$ & $47.80 \%$ & $54.20 \%$ \\
\hline Mullerian mixed tumour of ovary & 0 & $\mathrm{NE}$ & $\mathrm{NE}$ & $\mathrm{NE}$ & 3 & $66.77 \%$ & $5.35 \%$ & $94.58 \%$ & 904 & $26.93 \%$ & $23.65 \%$ & $30.32 \%$ & 1,335 & $17.45 \%$ & $14.97 \%$ & $20.08 \%$ \\
\hline Non epithelial tumours of ovary & 298 & $94.95 \%$ & $91.34 \%$ & $97.08 \%$ & 666 & $91.80 \%$ & $89.23 \%$ & $93.77 \%$ & 2,192 & $83.91 \%$ & $82.06 \%$ & $85.57 \%$ & 750 & $63.28 \%$ & $58.29 \%$ & $67.85 \%$ \\
\hline Sex cord tumours of ovary & $\underline{11}$ & $78.03 \%$ & $35.35 \%$ & $94.25 \%$ & $\underline{52}$ & $68.34 \%$ & $52.73 \%$ & $79.74 \%$ & 1,280 & $83.87 \%$ & $81.32 \%$ & $86.10 \%$ & 594 & $70.14 \%$ & $64.44 \%$ & $75.11 \%$ \\
\hline Granulosa cell tumours malign & 8 & $71.71 \%$ & $25.17 \%$ & $92.30 \%$ & 35 & $64.93 \%$ & $45.26 \%$ & $79.04 \%$ & 1,165 & $84.76 \%$ & $82.12 \%$ & $87.05 \%$ & 533 & $71.29 \%$ & $65.24 \%$ & $76.48 \%$ \\
\hline & 3 & NE & $\mathrm{NE}$ & NE & 11 & $71.86 \%$ & $35.46 \%$ & $90.00 \%$ & 44 & $73.96 \%$ & $55.21 \%$ & & 16 & $48.20 \%$ & $20.55 \%$ & $71.41 \%$ \\
\hline Other sec cord tumours of o & 0 & $\mathrm{NE}$ & NE & $\mathrm{NE}$ & 6 & $83.44 \%$ & $27.06 \%$ & $97.53 \%$ & 71 & $75.12 \%$ & $61.34 \%$ & & 45 & $64.85 \%$ & $41.14 \%$ & $80.96 \%$ \\
\hline Germ cell tumour of ovary & $\underline{287}$ & $95.60 \%$ & $\underline{92.06 \%}$ & $\underline{97.58 \%}$ & $\underline{614}$ & $93.76 \%$ & $91.30 \%$ & $95.54 \%$ & $\underline{912}$ & $83.92 \%$ & $81.17 \%$ & $86.31 \%$ & $\underline{156}$ & $36.60 \%$ & $\underline{26.87 \%}$ & $46.37 \%$ \\
\hline Yolk sac tumors & 51 & $96.03 \%$ & $84.49 \%$ & $99.03 \%$ & 101 & $91.80 \%$ & $84.08 \%$ & $95.87 \%$ & 141 & $83.43 \%$ & $75.83 \%$ & $88.82 \%$ & 9 & $\mathrm{NE}$ & $\mathrm{NE}$ & $\mathrm{NE}$ \\
\hline Dysgerminoma & 101 & $100.08 \%$ & NE & $\mathrm{NE}$ & 290 & $95.85 \%$ & $92.43 \%$ & $97.74 \%$ & 244 & $85.56 \%$ & $79.98 \%$ & $89.68 \%$ & 24 & $29.97 \%$ & $10.09 \%$ & $53.09 \%$ \\
\hline Mixed germ cell tumors & 21 & $90.15 \%$ & $65.73 \%$ & $97.47 \%$ & 32 & $85.96 \%$ & $65.83 \%$ & $94.68 \%$ & 30 & $81.69 \%$ & $59.59 \%$ & $92.40 \%$ & 2 & $\mathrm{NE}$ & $\mathrm{NE}$ & $\mathrm{NE}$ \\
\hline $\begin{array}{l}\text { Malignant/Immature teratomas of } \\
\text { ovary }\end{array}$ & 102 & $96.34 \%$ & $88.63 \%$ & $98.86 \%$ & 175 & $94.70 \%$ & $89.87 \%$ & $97.26 \%$ & 436 & $86.28 \%$ & $82.40 \%$ & $89.35 \%$ & 116 & $41.99 \%$ & $30.39 \%$ & $53.14 \%$ \\
\hline Other germ cell tumours of ovary & 12 & $65.83 \%$ & $32.40 \%$ & $85.63 \%$ & 16 & $78.22 \%$ & $45.97 \%$ & $92.53 \%$ & 61 & $62.07 \%$ & $47.02 \%$ & $73.98 \%$ & 5 & $25.66 \%$ & $0.72 \%$ & $68.74 \%$ \\
\hline
\end{tabular}

NE: not estimable because no cases were observed in the period (2000-2007) 
Figure 1, Five-year Relative Survival for rare epithelial and non epithelial ovarian cancer with 95\% Confidence Intervals by European area

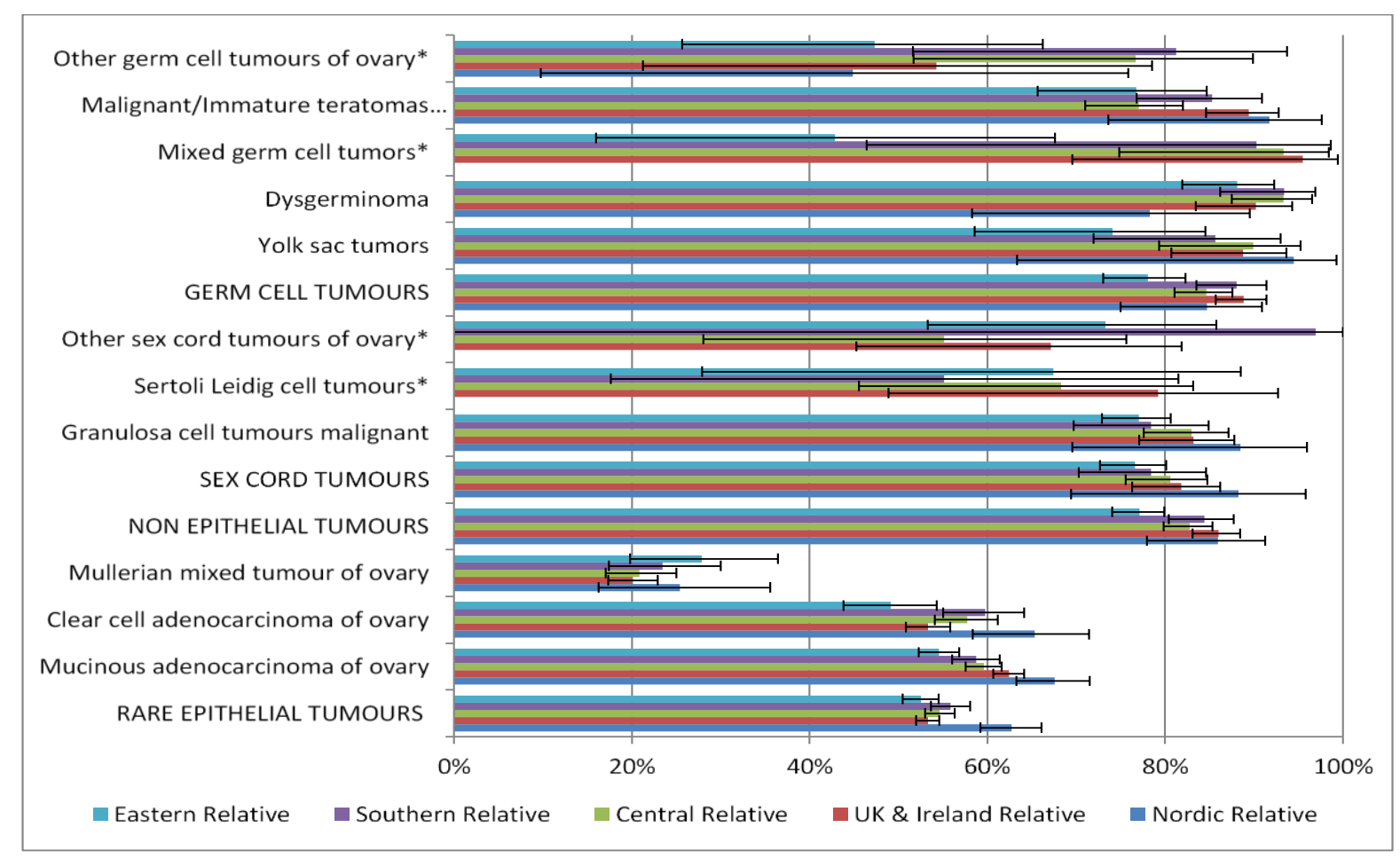

*: analyses based on $<50$ cases

Figure 2. EURACAN targeted rare adult cancer (The governance)
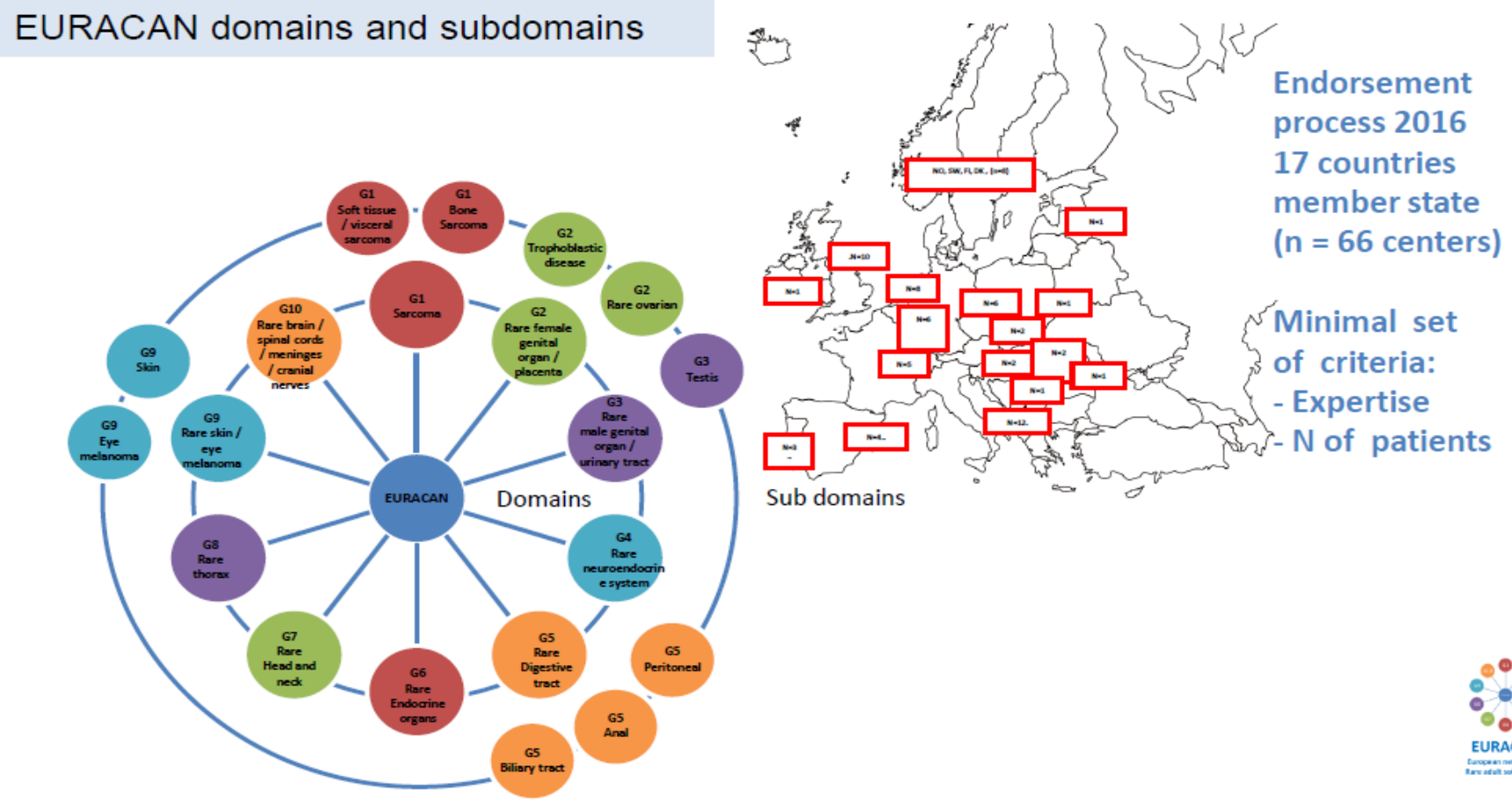

Sub domains 


\section{References:}

\section{Reference List}

(1) Gatta G, van der Zwan JM, Casali PG, Siesling S, Dei Tos AP, Kunkler I et al. Rare cancers are not so rare: the rare cancer burden in Europe. Eur J Cancer 2011 November;47(17):2493-511.

(2) Mackay HJ, Brady MF, Oza AM, Reuss A, Pujade-Lauraine E, Swart AM et al. Prognostic relevance of uncommon ovarian histology in women with stage III/IV epithelial ovarian cancer. Int J Gynecol Cancer 2010 August;20(6):945-52.

(3) Alexandre J, Ray-Coquard I, Selle F, Floquet A, Cottu P, Weber B et al. Mucinous advanced epithelial ovarian carcinoma: clinical presentation and sensitivity to platinum-paclitaxel-based chemotherapy, the GINECO experience. Ann Oncol 2010 December;21(12):2377-81.

(4) Ferlay J, Parkin DM, Steliarova-Foucher E. Estimates of cancer incidence and mortality in Europe in 2008. Eur J Cancer 2010 March;46(4):765-81.

(5) Ray-Coquard I, Weber B, Lotz JP, Tournigand C, Provencal J, Mayeur D et al. Management of rare ovarian cancers: the experience of the French website "Observatory for rare malignant tumours of the ovaries" by the GINECO group: interim analysis of the first 100 patients. Gynecol Oncol 2010 October;119(1):53-9.

(6) Derbel O, Heudel PE, Cropet C, meeus P, Vaz G, Biron P et al. Survival impact of centralization and clinical guidelines for soft tissue sarcoma (A prospective and exhaustive population-based cohort). PLoS ONE 2017;12(2):e0158406.

(7) Mallone S, de AR, van der Zwan JM, Trama A, Siesling S, Gatta G et al. Methodological aspects of estimating rare cancer prevalence in Europe: the experience of the RARECARE project. Cancer Epidemiol 2013 December;37(6):850-6.

(8) Sant M, Allemani C, Santaquilani M, Knijn A, Marchesi F, Capocaccia R. EUROCARE-4. Survival of cancer patients diagnosed in 1995-1999. Results and commentary. Eur J Cancer 2009 April;45(6):931-91.

(9) Gatta G, Ciccolallo L, Kunkler I, Capocaccia R, Berrino F, Coleman MP et al. Survival from rare cancer in adults: a population-based study. Lancet Oncol 2006 February;7(2):132-40.

(10) Capocaccia R, Colonna M, Corazziari I, de AR, Francisci S, Micheli A et al. Measuring cancer prevalence in Europe: the EUROPREVAL project. Ann Oncol 2002 June;13(6):831-9. 
(11) Gatta G, van der Zwan JM, Casali PG, Siesling S, Dei Tos AP, Kunkler I et al. Rare cancers are not so rare: the rare cancer burden in Europe. Eur J Cancer 2011 November;47(17):2493-511.

(12) Ray-Coquard I, Weber B, Lotz JP, Tournigand C, Provencal J, Mayeur D et al. Management of rare ovarian cancers: the experience of the French website "Observatory for rare malignant tumours of the ovaries" by the GINECO group: interim analysis of the first 100 patients. Gynecol Oncol 2010 October;119(1):53-9.

(13) Chiannilkulchai N, Pautier P, Genestie C, Bats AS, Vacher-Lavenu MC, vouassouxShisheboran $\mathrm{M}$ et al. Networking for ovarian rare tumors: a significant breakthrough improving disease management. Ann Oncol 2017 April 7.

(14) du BA, Rochon J, Lamparter C, Pfisterer J. [Impact of center characteristics on outcome in ovarian cancer in Germany]. Zentralbl Gynakol 2005 February;127(1):18-30.

(15) Ray-Coquard I, Weber B, Lotz JP, Tournigand C, Provencal J, Mayeur D et al. Management of rare ovarian cancers: the experience of the French website "Observatory for rare malignant tumours of the ovaries" by the GINECO group: interim analysis of the first 100 patients. Gynecol Oncol 2010 October;119(1):53-9.

(16) Chiannilkulchai N, Pautier P, Genestie C, Bats AS, Vacher-Lavenu MC, vouassouxShisheboran $\mathrm{M}$ et al. Networking for ovarian rare tumors: a significant breakthrough improving disease management. Ann Oncol 2017 April 7.

(17) Ray-Coquard I, Ledermann J. International Journal of Gynecological Cancer. Editorial. Int J Gynecol Cancer 2014 November;24(9 Suppl 3):S2-S4.

(18) Ledermann JA, Ray-Coquard I. Novel approaches to improve the treatment of rare gynecologic cancers: research opportunities and challenges. Am Soc Clin Oncol Educ Book 2014;e282-e286.

(19) Billingham L, Malottki K, Steven N. Research methods to change clinical practice for patients with rare cancers. Lancet Oncol 2016 February;17(2):e70-e80.

(20) Parmar MK, Sydes MR, Morris TP. How do you design randomised trials for smaller populations? A framework. BMC Med 2016 November 25;14(1):183.

(21) Buzyn A, Blay JY, Hoog-Labouret N, Jimenez M, Nowak F, Deley MC et al. Equal access to innovative therapies and precision cancer care. Nat Rev Clin Oncol 2016 June;13(6):385-93.

(22) Sleijfer S, Wagner AJ. The challenge of choosing appropriate end points in single-arm phase II studies of rare diseases. J Clin Oncol 2012 March 20;30(9):896-8.

(23) Rosner GL, Berry DA. A Bayesian group sequential design for a multiple arm randomized clinical trial. Stat Med 1995 February 28;14(4):381-94.

(24) Rosner GL, Stadler W, Ratain MJ. Randomized discontinuation design: application to cytostatic antineoplastic agents. J Clin Oncol 2002 November 15;20(22):4478-84. 
(25) Chiannilkulchai N, Pautier P, Genestie C, Bats AS, Vacher-Lavenu MC, vouassouxShisheboran $\mathrm{M}$ et al. Networking for ovarian rare tumors: a significant breakthrough improving disease management. Ann Oncol 2017 April 7.

(26) Trimble EL, Birrer MJ, Hoskins WJ, Marth C, Petryshyn R, Quinn M et al. Current academic clinical trials in ovarian cancer: Gynecologic Cancer Intergroup and US National Cancer Institute Clinical Trials Planning Meeting, May 2009. Int J Gynecol Cancer 2010 October;20(7):1290-8.

(27) Keat N, Law K, McConnell A, Seymour M, Welch J, Trimble T et al. International Rare Cancers Initiative (IRCI). Ecancermedicalscience 2013 May 21;7:ed20. doi: 10.3332/ecancer.2013.ed20. eCollection;\%2013.:ed20.

(28) Bogaerts J, Sydes MR, Keat N, McConnell A, Benson A, Ho A et al. Clinical trial designs for rare diseases: studies developed and discussed by the International Rare Cancers Initiative. Eur J Cancer 2015 February;51(3):271-81.

(29) Seckl MJ, Sebire NJ, Berkowitz RS. Gestational trophoblastic disease. Lancet 2010 August 28;376(9742):717-29.

(30) Mangili G, Lorusso D, Brown J, Pfisterer J, Massuger L, Vaughan M et al. Trophoblastic disease review for diagnosis and management: a joint report from the International Society for the Study of Trophoblastic Disease, European Organisation for the Treatment of Trophoblastic Disease, and the Gynecologic Cancer InterGroup. Int J Gynecol Cancer 2014 November;24(9 Suppl 3):S109-S116.

31 European Commission. Communication no. 679/2008 of 11 November 2008 to the European Parliament, the Council, the European Economic and Social Committee and the Committee of the Regions on Rare Diseases: Europe's challenges; 2008

32 http://www.istitutotumori.mi.it/rtr.htm, last access April 2013

33 Institute National du Cancer (INCA). Rare Adult Cancers: organization into expert centres (September 2012). Available from http://www.e-cancer.fr/soins/prises-encharge-specifiques/cancers-rares/une-nouvelle-organisation, last access April 2013.

34 www.rarecarenet.eu/rarecarenet, last access April 2013. 